\title{
Mineralogia dos greisens da área Grota Rica, Plúton Água Boa, Pitinga, Amazonas
}

\author{
Gilmara Regina Lima Feio ${ }^{1,2}$, Roberto Dall'Agnol, ${ }^{1,2}$, Régis Munhoz Krás Borges ${ }^{1}$, \\ Hilton Tulio Costi ${ }^{1,3}$ \& Claudio Nery Lamarão ${ }^{1,2}$
}

\begin{abstract}
Resumo O topázio-álcali-feldspato-granito, fácies mais evoluída do plúton Água Boa, foi afetado por processos de alteração hidrotermal, que culminaram com a formação de greisens e veios de quartzo, principais hospedeiros de mineralizações de Sn e, subordinadamente, $\mathrm{Zn}$. Os greisens foram classificados como quartzotopázio-siderofilita-greisen, topázio-siderofilita-quartzo-greisen e topázio-quartzo-greisen. São compostos por quartzo, siderofilita e topázio, acompanhados por quantidades variáveis de fluorita, zinnwaldita, esfalerita, cassiterita, zircão, anatásio e, localmente, Ce-monazita, galena, pirita, calcopirita e bismuto nativo. Estudos de química mineral em microssonda eletrônica permitiram identificar três tipos de micas: (1) siderofilita marrom, presente no topázio-granito; (2) siderofilita verde, encontrada nos greisens; (3) zinnwaldita, fracamente colorida, encontrada como coroas finas e descontínuas em torno da siderofilita verde dos greisens, e encontrada também em veios de quartzo. A composição da siderofilita do granito varia com a proximidade dos greisens, mostrando uma evolução de siderofilita $\rightarrow$ siderofilita litinífera, com aumento nos conteúdos de ${ }^{\mathrm{VI}} \mathrm{Al}$, Li e Si. A siderofilita do greisen foi, por sua vez, parcialmente substituída por zinnwaldita, também com aumento nos teores de ${ }^{\mathrm{VI}} \mathrm{Al}, \mathrm{Li}$ e $\mathrm{Si}$. A cassiterita nos greisens forma cristais euédricos a subédricos em contato reto com siderofilita ou como agregados junto com topázio, quartzo e fluorita. Exibe cristais maclados, zonados e com forte pleocroísmo. As composições muito puras e baixos conteúdos de $\mathrm{Nb}$ e Ta, indicam formação em condições hidrotermais.
\end{abstract}

Palavras-chave: topázio-álcali-feldspato-granito, greisens, química mineral, Província Estanífera de Pitinga.

\begin{abstract}
Mineralogy of the greisens of the Grota Rica area, Agua Boa Pluton, Pitinga, Amazonas state. The topaz-alkali-feldspar-granite, the most evolved facies of the Água Boa pluton, was affected by hydrothermal alteration, represented by greisens and quartz veins, the main host for $\mathrm{Sn}$ - and subordinated $\mathrm{Zn}$ mineralization. The greisens are classified as quartz-topaz-siderophyllite-greisen, topaz-siderophyllite-greisen and quartztopaz-quartz-greisen. They are composed essentially of quartz, topaz and siderophyllite, accompanied by variable amounts of fluorite, zinnwaldite, sphalerite, cassiterite, zircon and anatase and locally Ce-monazite, galena, pyrite, chalcopyrite and native bismuth. EMPA studies allowed identifying three types of micas: (1) brown siderophyllite from topaz-granite; (2) the green siderophyllite of greisens and (3) zinnwaldite, weakly colored, found as thin and discontinuous rims around green siderophyllite, and quartz vein. The siderophyllite composition of the granite towards greisens shows an evolution of siderophyllite to Li-siderophyllite with increase of ${ }^{\mathrm{VI}} \mathrm{Al}, \mathrm{Li}$ and $\mathrm{Si}$ contents. On the other hand, the siderophyllite of the greisen was partially replaced by zinnwaldite, with increase of ${ }^{\mathrm{VI}} \mathrm{Al}, \mathrm{Li}$ and $\mathrm{Si}$ contents. The cassiterite in the greisens forms euhedral to subeuhedral, twin and zoned crystals, with strong pleochroism. It occurs as aggregates together with topaz, quart and fluorite. The pure composition and the low content of the $\mathrm{Nb}$ and $\mathrm{Ta}$ of cassiterite indicate hydrothermal conditions
\end{abstract}

Keywords: topaz-alkali-feldspar-granite, greisen, mineral chemistry, Pitinga Tin Province.

INTRODUÇÃo A Província Estanífera de Pitinga se caracteriza por hospedar depósitos minerais polimetálicos em dois plútons graníticos tipo-A, paleoproterozoicos, altamente fracionados, Madeira (Horbe et al. 1985, 1991, Minuzzi 2005, Minuzzi et al. 2008, Costi et al. 2009) e Água Boa (Lenharo et al. 2003, Borges et al. 2009). As mineralizações estão hospedadas na fácies albita-granito do plúton Madeira (cassiterita magmática, criolita, pirocloro, columbita e zircão), e em greisens e epissienitos sódicos associados ao plúton Água Boa (cassiterita hidrotermal e esfalerita).

Apesar da reconhecida importância dos greisens e outras rochas hidrotermalizadas na origem dos depósitos de cassiterita associados a granitos tipo-A do Cráton Amazônico, há poucos estudos que tenham se dedicado a uma melhor caracterização da mineralogia

1 - Grupo de Pesquisa Petrologia de Granitoides, Universidade Federal do Pará, Belém (PA), Brasil. E-mail: gilmara@ufpa.br, robdal@ufpa.br, munhoz@ufpa.br, tulio@museu-goeldi.br, lamarão@ufpa.br

2 - Programa de Pós-Graduação em Geologia e Geoquímica, Universidade Federal do Pará, Belém (PA), Brasil.

3 - Museu Paraense Emílio Goeldi (MPEG), Belém (PA), Brasil. 
destas rochas. Neste sentido, merecem destaque alguns trabalhos efetuados em granitos da Província Rondoniana (Sparrenberger 2003, Souza \& Botelho 2002). Em termos da Província Estanífera de Pitinga, foi publicado estudo sobre a cassiterita associada aos diferentes tipos de depósitos da província (Costi et al. 2000) e feita comparação entre os últimos e os depósitos estaníferos de Goiás (Lenharo et al. 2002). Greisens portadores de cassiterita, associados às diversas fácies do plúton Água Boa, foram estudados por Borges et al. (2003, 2009), Feio (2007) e Feio et al. (2007).

Embora, micas (siderofilita e fengita) de greisens associados ao granito rapakivi, fácies menos evoluída do plúton Água Boa, tenham sido caracterizadas e discutidas por Borges et al. (2003), micas de greisens associadas a outras fácies do plúton Água Boa, em especial da fácies mais evoluída - Topázio-granito - não tiveram a mesma atenção. Com o intuito de contribuir para um melhor conhecimento dos greisens hospedeiros de mineralizações estaníferas relacionados com granitos tipo-A, este artigo procura discutir com maior profundidade a mineralogia e a química mineral de greisens e veios de quartzo associados ao topázio-granito, fácies mais evoluída do plúton Água Boa, na área de Grota Rica da Província Estanífera de Pitinga. Tais greisens são rochas metassomáticas formadas por alteração de topázio-granito. Consistem dominantemente de quartzo, topázio e micas (siderofilita e zinnwaldita) e são hospedeiros de cassiterita e sulfetos, em especial esfalerita.
CONTEXTO GEOLÓGICO REGIONAL A mina de Pitinga localiza-se a $300 \mathrm{~km}$ a norte da cidade de Manaus, no estado do Amazonas (Fig. 1a). Quanto ao ambiente tectônico, situa-se na porção sul do Escudo das Guianas, parte integrante do Cráton Amazônico (Almeida et al. 1981, Gibbs \& Barron 1983). Nos modelos de províncias tectono-geocronológicas, a região localiza-se no limite entre as províncias Amazônia Central e Ventuari-Tapajós (Tassinari \& Macambira 2004) ou Tapajós-Parima (Santos et al. 2000).

Os granitoides da Suíte Intrusiva Água Branca apresentam idades entre 1,89-1,90 Ga (Pb-Pb evaporação, Almeida 2006, Valério et al. 2009) e são as rochas mais antigas da região de Pitinga. Encontram-se em contato com as rochas vulcânicas do Grupo Iricoumé, com idade de 1,88 Ga (Costi et al. 2000, Ferron et al. 2006). Na região de Pitinga (Fig. 1b), diversos corpos graníticos (granitos Simão, Rastro, Bom Futuro e Alto Pitinga), com idades $\mathrm{Pb}-\mathrm{Pb}$ em zircão similares às das rochas do Grupo Iricoumé, foram interpretados como os equivalentes plutônicos das unidades vulcânicas e agrupados sob a denominação de Suíte Mapuera (Ferron et al. 2006).

Dados isotópicos obtidos em granitos dos plútons Madeira, Água Boa e Europa revelaram idades em torno de 1,83-1,82 $\mathrm{Ga}(\mathrm{Pb}-\mathrm{Pb}$ evaporação, Costi et al. 2000, Lenharo 1998) e mostraram que tais granitos são significativamente mais jovens do que as suas encaixantes vulcânicas e do que os granitos da Suíte Mapuera, tendo sido agrupados sob a designação de Suíte Madeira (Costi et al. 2000).

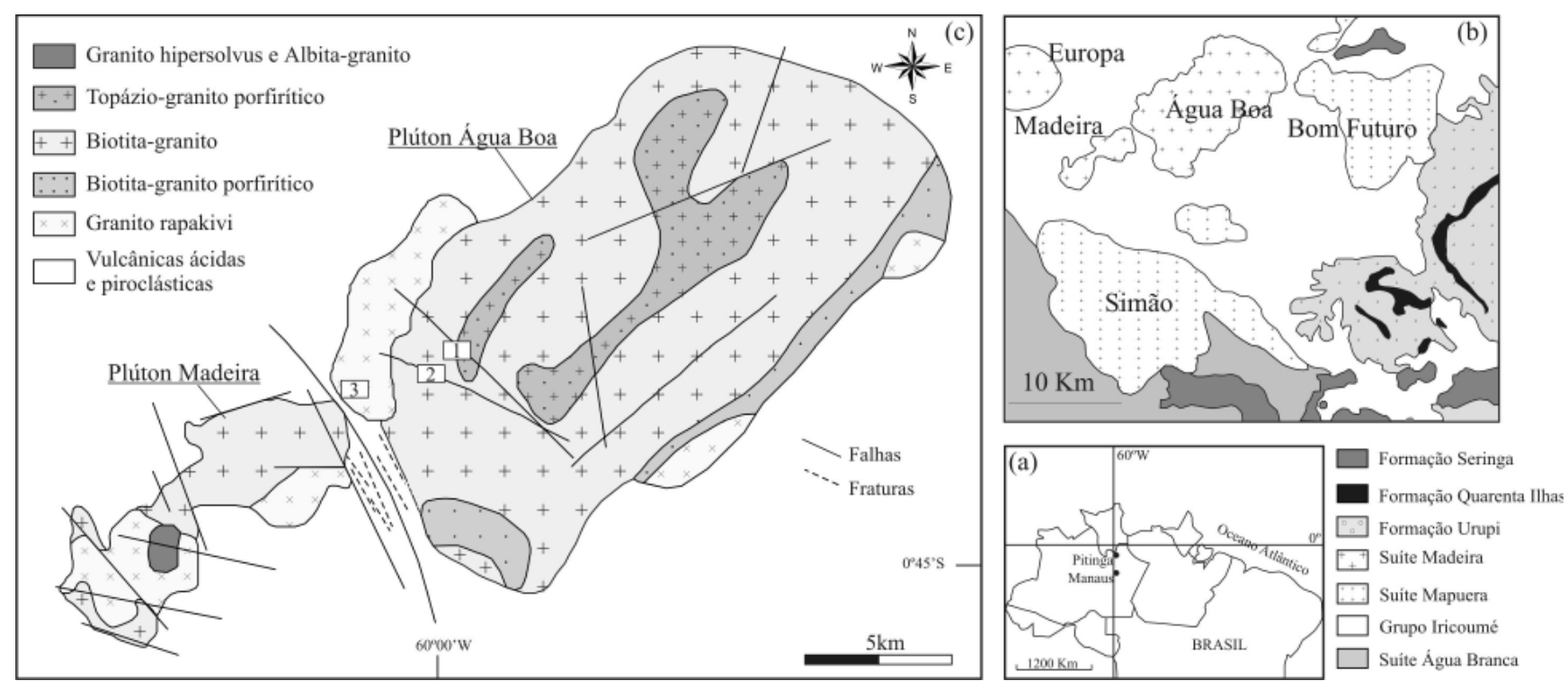

Figura 1 - Mapa Geológico dos granitos Madeira e Água Boa, destacando as áreas de ocorrência dos greisens. (a) Localização da mina Pitinga; (b) Mapa geológico simplificado da região de Pitinga, com distribuição dos granitos das Suites Madeira e Mapuera (Costi et al. 2000, Ferron 2006); (c) Mapa geológico dos granitos Madeira e Água Boa. Os números de 1 a 3 indicam a localização das ocorrências de rochas hidrotermalizadas (Feio et al. 2006, Costi et al. 2005): 1- Greisens associados ao topázio-granito (Feio et al. 2007), 2- Greisens e epissienitos sódicos associados ao biotita-granito (Costi et al. 2002), 3- Greisens e epissienito potássico associados ao granito rapakivi (Borges 1997, 2002). 
Tais unidades são recobertas pela sequência de sedimentos flúvio-eólicos continentais e rochas piroclásticas da Formação Urupi (Veiga Jr. et al. 1979), que, por sua vez, é intrudida por um conjunto de soleiras e diques toleiíticos da Formação Quarenta Ilhas (idade U-Pb de $1790 \pm 7 \mathrm{Ma}$; SHRIMP em badeleíta; Santos et al. 2002).

O último evento ígneo, identificado na província, corresponde ao magmatismo básico alcalino potássico da Formação Seringa, com idades de $1079 \pm 18 \mathrm{Ma}$ e $1090 \pm 13 \mathrm{Ma}$ (K-Ar em hornblenda; Araújo Neto \& Moreira 1976).

GEOLOGIA LOCAL O plúton Água Boa tem forma aproximadamente elíptica, alongada segundo a direção NE-SW e é intrusivo em rochas vulcânicas e piroclásticas do Grupo Iricoumé (Fig. 1c). É constituído por quatro fácies, sendo a mais precoce um hornblenda-biotita-álcali feldspato-granito de granulação média a grossa, que ocorre ao longo das bordas noroeste e sudeste do batólito. Mostra fenocristais de feldspato potássico com coroas de plagioclásio (textura rapakivi), sendo, em função disso, designado historicamente como granito rapakivi (Daoud \& Antonietto Jr. 1985). É composto por feldspato potássico pertítico, oligoclásio e quartzo, com proporções subordinadas de biotita e anfibólio e fluorita, zircão, opacos e apatita como minerais acessórios. A fácies colocada a seguir é representada pelo biotita-granito porfirítico, com fenocristais de feldspato potássico euédricos e matriz de granulação fina, que forma faixas alongadas e estreitas, disposta próximo às bordas do corpo (Fig. 1c). É hololeucocrático e composto essencialmente por feldspato potássico pertítico, quartzo e plagioclásio, com baixas proporções de biotita, fluorita e opacos. A seguir, deuse a colocação da fácies de maior extensão superficial no corpo, um biotita-álcali feldspato-granito médio a grosso, composto por mesopertita, quartzo e raro plagioclásio. A fácies mais tardia é representada por um topázio-granito seriado a porfirítico, situado em zona alongada na porção central do corpo (Lenharo 1998). É composto por fenocristais de quartzo e feldspato potássico em matriz de granulação média a fina. O principal mineral máfico é a biotita e os acessórios primários são topázio, zircão, fluorita e opacos.

Os depósitos hidrotermais de cassiterita associados ao plúton Água Boa estão alojados em: (1) quartzo-greisens encaixados em fraturas que cortam o biotita-álcali feldspato-granito (Daoud 1988); (2) siderofilita-topázio-greisens (Gs1), formado a temperaturas de inclusões fluidas em torno de 380 a $310^{\circ} \mathrm{C}$; e clorita-fengita-greisens (Gs2), onde se encontram as maiores concentrações de sulfetos. Estimativa de temperatura por inclusões fluidas forneceram temperaturas entre 270 e $100^{\circ} \mathrm{C}$. Tais greisens acham-se encaixados na fácies granito rapakivi, próximo ao seu contato com as rochas vulcânicas encaixantes (Borges 2002, Borges et al. 2009); (3) corpos lenticulares de epissienitos sódicos e siderofilita-greisens, formados em zonas metassomaticamente alteradas a partir da fácies biotita-granito (Costi et al. 2002, Feio et al. 2006); (4) topázio-siderofilita-greisens e leucogranitos pegmatíticos albitizados associados ao topázio-granito (Feio et al. 2007).

\section{ASPECTOS GEOLÓGICOS E PETROGRÁFI- COS DOS GREISENS DA ÁREA DE GROTA RICA}

A descrição detalhada da geologia e das características petrográficas do granito e das rochas hidrotermalizadas da área de Grota Rica foi apresentada por Feio et al. (2007). Em síntese, os greisens encontram-se condicionados a uma zona de fraturamento $(\sim 50 \mathrm{~m})$ orientada segundo N50W. Acham-se encaixados em biotita-álcali feldspato granito com topázio, de textura seriada ou porfirítica e que se mostra por vezes albitizado. Leucogranitos pegmatíticos com cassiterita ocorrem em contato com o biotita-álcali-feldspato-granito e ambos são truncados por topázio-greisen. Mostram expressiva albitização e apresentam cristais de esfalerita e topázio relacionados com a greisenização.

O biotita-álcali feldspato granito é um leucogranito de caráter hipersolvus (Tuttle \& Bowen 1958) e possui biotita $(\sim 0,5 \mathrm{~mm})$ como principal mineral máfico. Esta exibe pleocroísmo marrom a verde pálido e ocorre em agregados ou em lamelas subédricas, intersticiais aos cristais de quartzo e feldspato alcalino. Os minerais acessórios são topázio, que se apresenta em cristais subédricos a euédricos de granulação fina $(<0,8$ $\mathrm{mm}$ ), zircão, rutilo e ferro-columbita. A albitização no granito foi acompanhada pela formação de mica branca e diminuição nos conteúdos modais de quartzo.

Os greisens exibem cor preta a cinza médio e textura inequigranular fina a grossa. São compostos fundamentalmente por quartzo, siderofilita e topázio, acompanhados por quantidades variáveis de fluorita, zinnwaldita, esfalerita, cassiterita, zircão e anatásio, sendo classificados como quartzo-topázio-siderofilitagreisen, topázio-siderofilita-quartzo-greisen e topázioquartzo-greisen. Estudos de microscopia eletrônica de varredura revelaram a presença de Ce-monazita, galena, pirita, calcopirita e bismuto nativo. A cassiterita ocorre disseminada na rocha e forma agregados ou grãos isolados. A esfalerita forma cristais subédricos a anédricos, abundantes nos greisens mais ricos em siderofilita. Tais rochas são cortadas por veios de quartzo com esfalerita. A greisenização do biotita-álcali feldspato-granito é acompanhada por aumento nos conteúdos de topázio, mica e quartzo e diminuição do feldspato alcalino. Os granitos greisenizados apresentam coloração rosada a avermelhada e cavidades de dissolução.

No greisen, a mica possui pleocroísmo marcante de verde a verde pálido, é muito abundante (conteúdo modal variando de 35 a $17 \%$, exceto no topázioquartzo-greisen, onde é muito escassa $-<1 \%$ ) e se apresenta em agregados de cristais anédricos a subédricos. Comumente se observa o desenvolvimento de uma fina borda de mica tardia de cor amarelo pálido (< $5 \%$ ), envolvendo inteiramente a mica verde. Nos veios 
de quartzo, esta mesma mica tardia, ocorre como finos cristais euédricos incolores, englobados por esfalerita ou a ela associados.

MÉTODOS E TÉCNICAS UTILIZADAS As análises químicas de micas e cassiterita foram efetuadas no Instituto de Geociências da Universidade de São Paulo, por meio de uma microssonda eletrônica marca JEOL modelo JXA-8600, equipada com WDS (Wavelength Dispersive System). As condições operacionais utilizadas nestas análises foram: tensão de aceleração de 15 $\mathrm{kv}$, corrente do feixe de $20 \mathrm{nA}$, diâmetro do feixe de 5 $\mu \mathrm{m}$ e tempo de contagem do feixe de $10 \mathrm{~s}$.

Os óxidos analisados para as micas foram: $\mathrm{SiO}_{2}$, $\mathrm{Al}_{2} \mathrm{O}_{3}, \mathrm{TiO}_{2}, \mathrm{FeOt}, \mathrm{MnO}, \mathrm{MgO}, \mathrm{CaO}, \mathrm{Na}_{2} \mathrm{O}, \mathrm{K}_{2} \mathrm{O}, \mathrm{BaO}$, $\mathrm{ZnO}$, $\mathrm{F}$ e $\mathrm{Cl}$. O Li, não dosado pela microssonda, foi calculado a partir da equação $\mathrm{Li}_{2} \mathrm{O}=\left(0,287 * \mathrm{SiO}_{2}\right)$ 9,552 (Tindle \& Webb 1990), muito similar àquelas propostas por Tischendorf et al. (1997) e Moura \& Botelho (1994). A correção PAP foi aplicada em todas as fases minerais. As fórmulas estruturais das micas foram calculadas com base em 22 átomos de oxigênio. Para a cassiterita foram analisados: $\mathrm{SnO}_{2}, \mathrm{Nb}_{2} \mathrm{O}_{5}, \mathrm{Ta}_{2} \mathrm{O}_{5}, \mathrm{TiO}_{2}$, $\mathrm{Y}_{2} \mathrm{O}_{3}, \mathrm{FeOt}$ e as fórmulas estruturais foram calculadas com base em 2 átomos de oxigênio.

As observações texturais e as análises semiquantitativas por espectroscopia de energia dispersiva de raios-X (EDS) em esfalerita, anatásio, fluorita, monazita, bismuto nativo, pirita e galena, foram realizadas no Instituto de Geociências da Universidade Federal do Pará, em um microscópio eletrônico de varredura da marca LEO modelo 1430, sob condições de voltagem de $20 \mathrm{kv}$, diâmetro do feixe de $5 \mu \mathrm{m}$ e tempo de contagem do feixe de $30 \mathrm{~s}$.

\section{MINERALOGIA E QUÍMICA MINERAL}

Micas Composições químicas representativas das micas do topázio-granito, greisens e veios de quartzo são apresentadas na tabela 1. A mica do granito e aquela dominante nos greisens são bastante similares em composição, porém, a mica do granito apresenta conteúdos mais elevados de $\mathrm{TiO}_{2}, \mathrm{MgO}$ e $\mathrm{FeO}$ e mais baixos valores de $\mathrm{Li}_{2} \mathrm{O}$ e $\mathrm{F}$, bem como de $\mathrm{Al}_{2} \mathrm{O}_{3}$. Os conteúdos de $\mathrm{TiO}_{2}$ da mica do granito variam entre 0,77 e 1,49\%, enquanto que aqueles da mica dominante nos greisens são sempre inferiores a $0,48 \%$. As micas tardias dos greisens e dos veios de quartzo são, comparativamente às anteriores, enriquecidas em sílica e, ligeiramente, em $\mathrm{Al}_{2} \mathrm{O}_{3}, \mathrm{~K}_{2} \mathrm{O}$ e $\mathrm{F}$ e empobrecidas em $\mathrm{FeO}$. Os teores de $\mathrm{Li}_{2} \mathrm{O}$ calculados também são mais elevados em decorrência de sua vinculação direta com a sílica.

Com base em sua composição química, a mica do topázio-granito e a dominante no greisen corresponderiam a variedades de siderofilita-protolitionita da série siderofilita-polilitionita (Foster 1960, modificado com os campos de Stone et al. 1988). Porém, seguindo os critérios de classificação propostos pela International Mineralogical Association (Rieder et al. 1998) estas micas seriam classificadas como siderofilita litinífera, sendo esta a denominação adotada no presente trabalho (Fig. 2a). Por sua vez, a mica tardia dos greisens e aquela dos veios de quartzo são classificadas como zinnwaldita (Fig. 2a). As duas variedades de micas tendem a se alinhar segundo o trend da série siderofilita-trilitionita, porém, há uma descontinuidade composicional entre elas (Fig. 2a).

No diagrama mgli-feal [(Mg-Li) vs. $\left.\left(\mathrm{Fe}^{+2}+\mathrm{Mn}+\mathrm{Ti}+\mathrm{Zn}\right){ }^{-\mathrm{VI}} \mathrm{Al}\right]$ (Tischendorf et al. 1997), modificado pela exclusão do campo da protolitionita $\mathrm{e}$

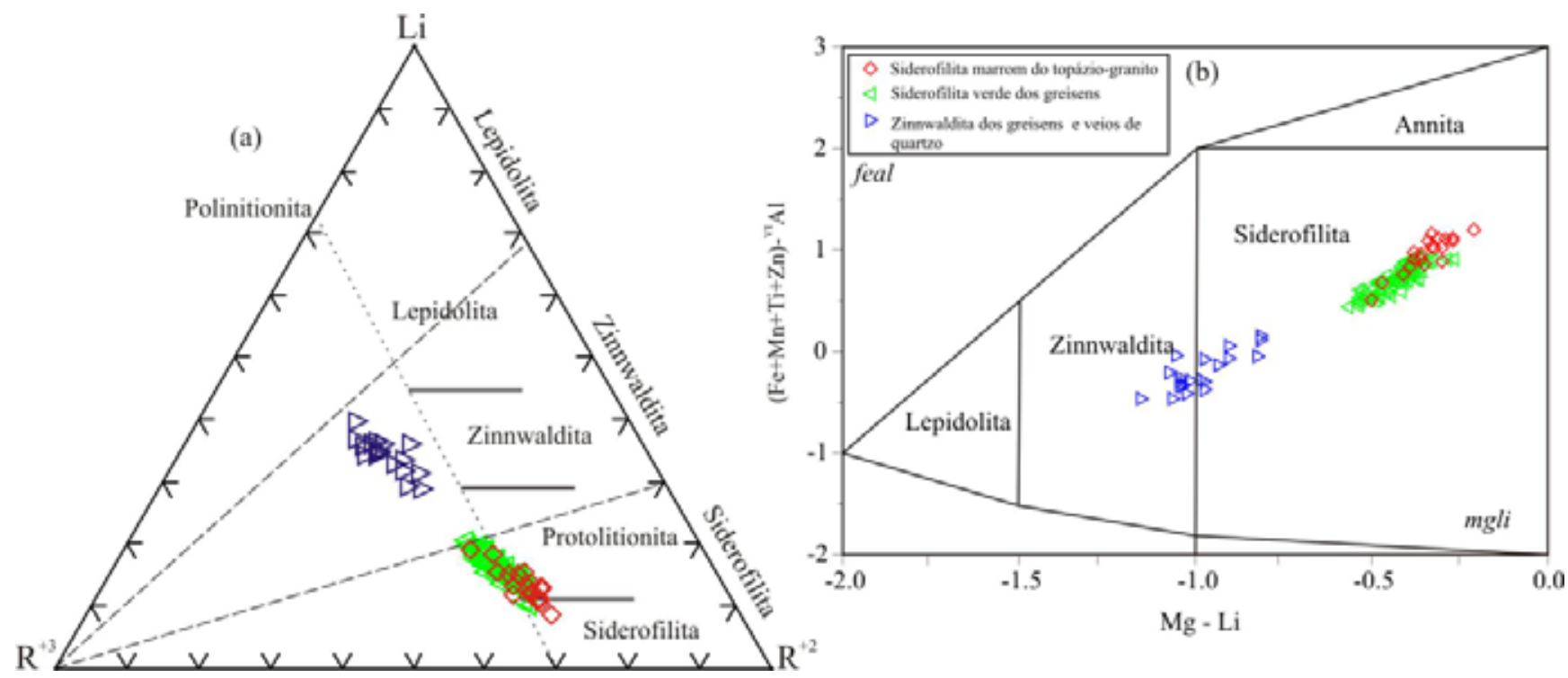

Figura 2 - Variação composicional das micas da área Grota Rica: (a) diagrama triangular Li $-R^{+3}-R^{+2}$ (Foster 1960, modificado com os campos de Stone et al. 1988). $R^{+3}={ }^{V I} A l+T i ; R^{+2}=F e^{+2}+M n+M g+Z n$. (b) diagrama (MgLi) vs. $\left[\left(\mathrm{Fe}^{+2}+\mathrm{Mn}+\mathrm{Ti}+\mathrm{Zn}\right){ }_{-}{ }^{V I} \mathrm{Al}\right]$ (Tischendorf et al. 2004). 


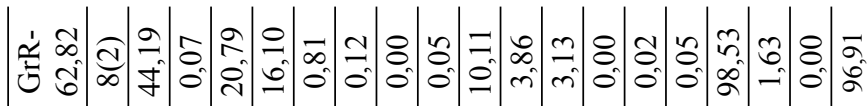

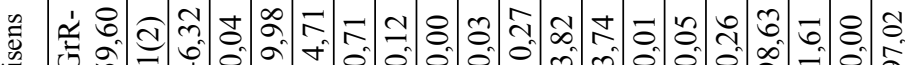
焉

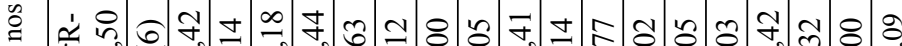

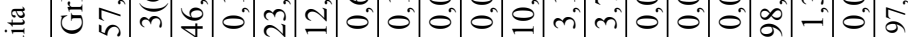

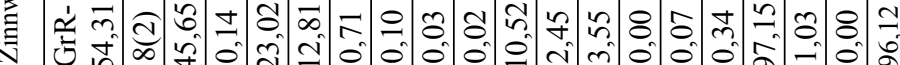

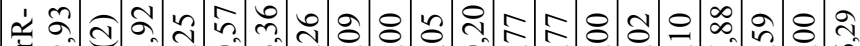

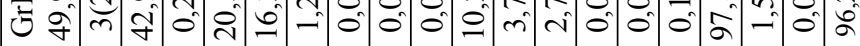

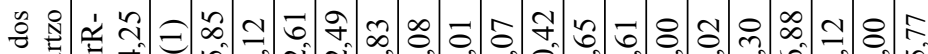

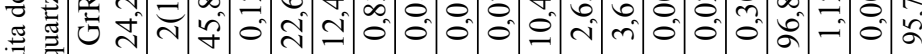
$\frac{\pi}{2}$

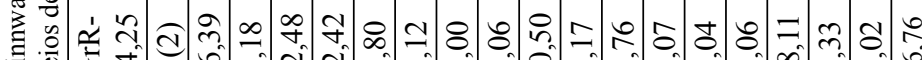

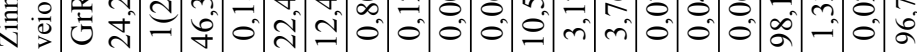

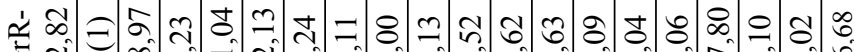

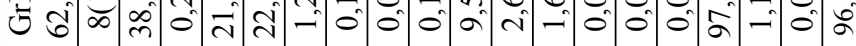

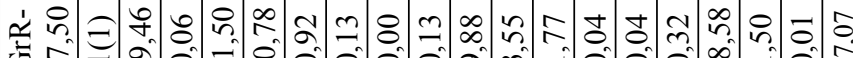

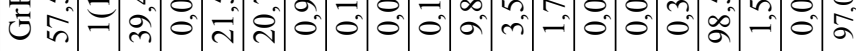

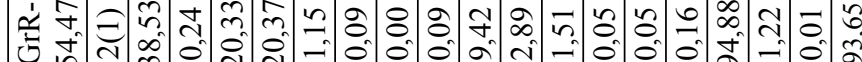
(5)

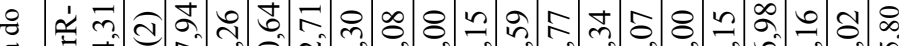

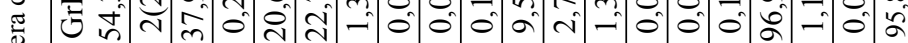
具 竞 is क

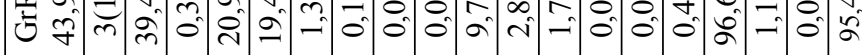

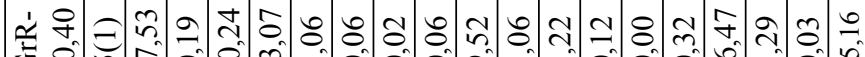

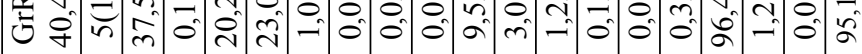

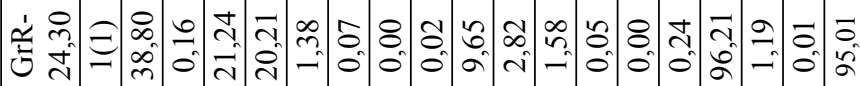
눈

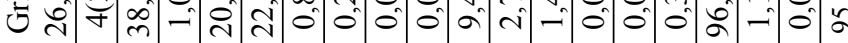

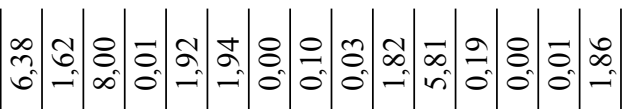

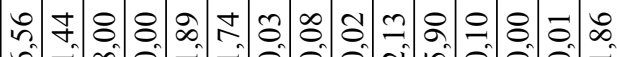

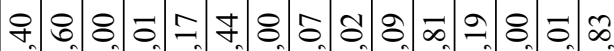
రु. ऊ.

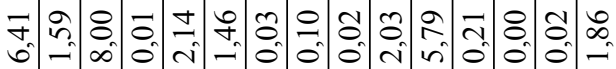

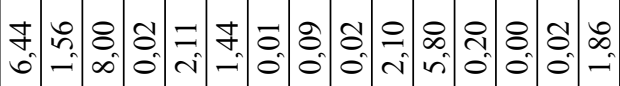

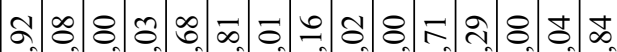
ni 400 क $\therefore$ ㄴ. 8 :

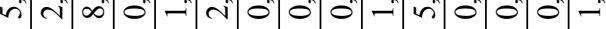
రి

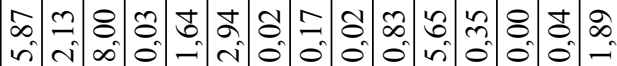
2. b.

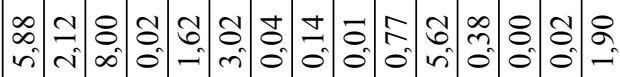

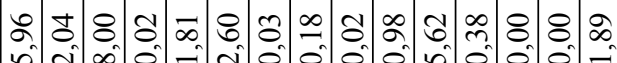

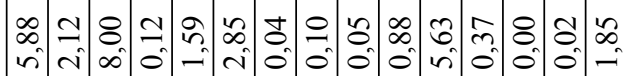

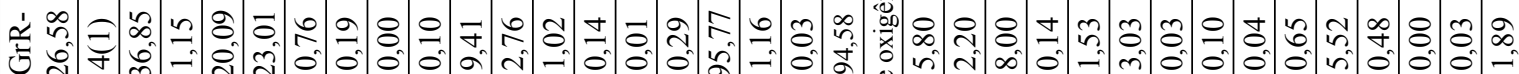
. ش 苟 is

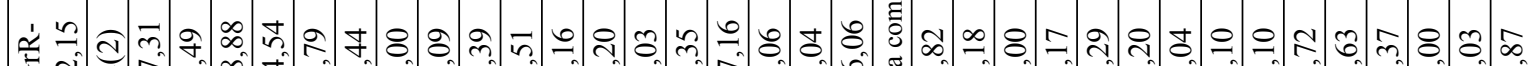

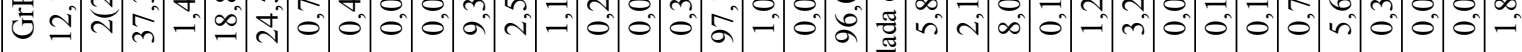

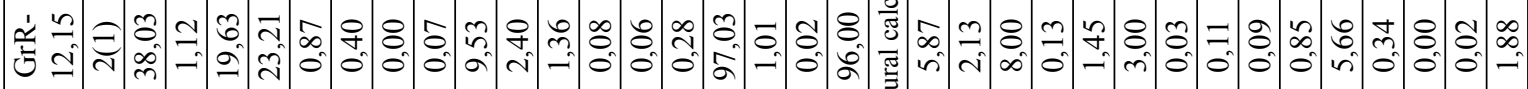

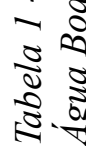

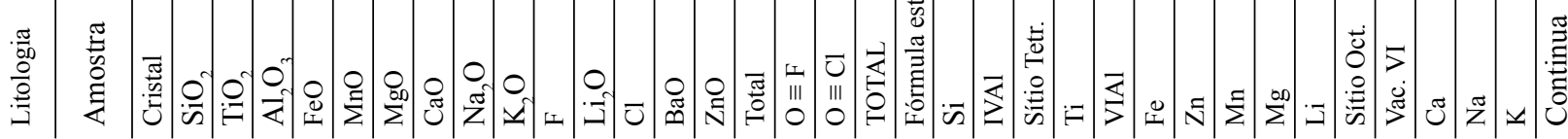




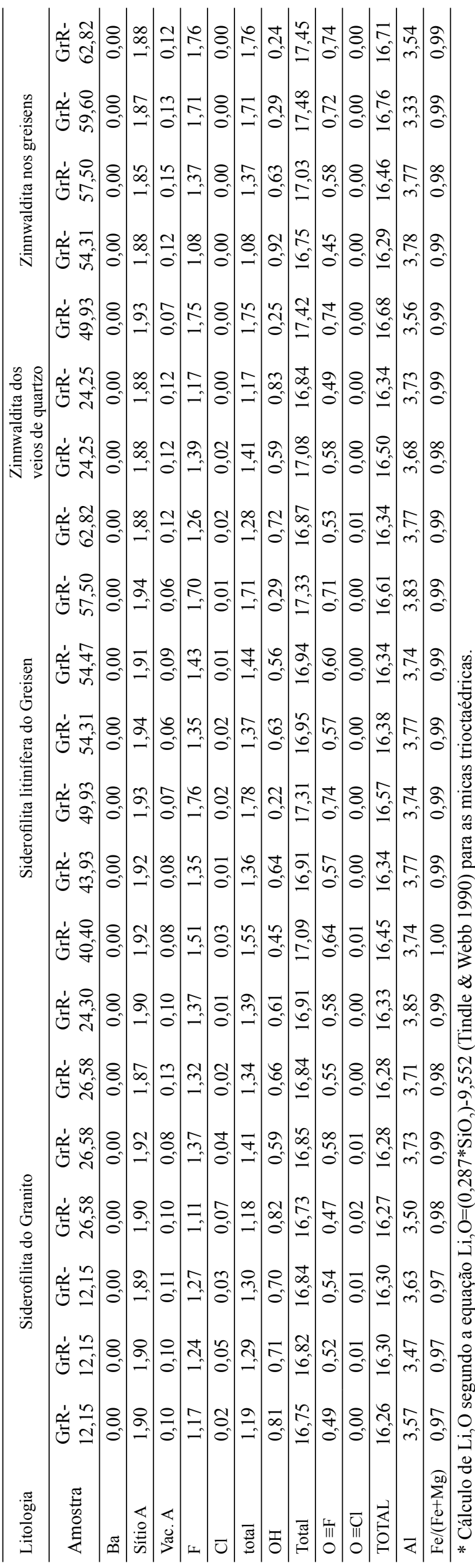

adição do campo da annita (Tischendorf et al. 2004), verifica-se que: (1) a mica marrom do topázio-granito e a mica verde dominante nos greisens se situam no campo da siderofilita; (2) a mica tardia dos greisens e aquela dos veios de quartzo incidem na transição entre os campos da zinnwaldita e da siderofilita (Fig. 2b).

SUBSTITUIÇÕES CATIÔNICAS A grande complexidade química das séries de substituição entre as micas ferrosas litiníferas fica muito bem evidenciada nos trabalhos de Cerný \& Burt (1984) e Sun \& Yu (1999). O diagrama da figura 3a representa o arcabouço composicional $\mathrm{Li}, \mathrm{Si}, \mathrm{Al}_{\mathrm{T}}\left({ }^{\mathrm{IV}} \mathrm{Al}+{ }^{\mathrm{VI}} \mathrm{Al}\right)$ e $\mathrm{Fe}_{\mathrm{T}}\left(\mathrm{Fe}^{+2}+\mathrm{Mg}+\mathrm{Mn}+\mathrm{Zn}\right)$ para micas trioctaédricas considerando a vacância zero (Cerný \& Burt 1984). Foram lançadas neste diagrama, as composições médias aproximadas das micas estudadas, já que não existe um equilíbrio perfeito entre os diferentes elementos nas composições reais. Apesar desta limitação, tal diagrama permite compreender melhor as variações químicas apresentadas por essas micas e o trend de substituição que teria controlado a evolução das siderofilitas litiníferas. Constata-se que, partindo da mica do granito para a dos greisens, há um aumento nos conteúdos de $\mathrm{Li}$ e $\mathrm{Si}$ e diminuição de $\mathrm{Fe}$, mantendo-se Al constante (Fig. 3a). A mica dos veios de quartzo e das bordas das siderofilitas exibe conteúdo similar de $\mathrm{Al}_{\mathrm{t}}$, mas é enriquecida comparativamente em $\mathrm{Si}$ e Li e empobrecida proporcionalmente em $\mathrm{Fe}_{\mathrm{t}}$ (Fig. 3a).

Sun \& Yu (1999) propuseram representar a ampla variação composicional das micas de Fe-Al-Li em espaço tridimensional. De acordo com Sun \& Yu (1999) as substituições apresentadas entre as siderofilitas apontam para uma evolução geral de siderofilita 1 (mica marrom do granito) para siderofilita 0 (mica verde dos greisens), correspondente à combinação dos vetores AM (annita-muscovita) e ET (Fe-eastonita-trilitionita), cujas equações de substituição são:

$$
\begin{aligned}
& 3^{\mathrm{VI}} \mathrm{R}^{+2} \rightarrow 2^{\mathrm{VI}} \mathrm{R}^{+3}+{ }^{\mathrm{VI}} \square \\
& 4 \mathrm{Fe}+2^{\mathrm{IV}} \mathrm{Al} \rightarrow 2 \mathrm{Si}+{ }^{\mathrm{VI}} \mathrm{Al}+3 \mathrm{Li}
\end{aligned}
$$

Substituindo $\mathrm{R}^{+2}$ por $\mathrm{Fe}$ e $\mathrm{R}^{+3}$ por $\mathrm{Al}$ e assumindo que as equações (1) e (2) são representativas das substituições observadas na siderofilita partindo do granito para o greisen e combinando-as, o resultado final é expresso por:

$$
7 \mathrm{Fe}+2^{\mathrm{IV}} \mathrm{Al}=2 \mathrm{Si}+3^{\mathrm{VI}} \mathrm{Al}+3 \mathrm{Li}+{ }^{\mathrm{VI}} \square
$$

Borges et al. (2003) discutiram as variações composicionais observadas nas micas ferrosas litiníferas dos greisens associados à fácies hornblenda-biotita-álcali feldspato-granito rapakivi da área Guinho-Baixão. Eles sugeriram que o mecanismo de substituição entre as siderofilitas se deu entre os vetores Fe-eastonita-trilitionita (ET) e annita-trilitionita (AT) de Sun \& Yu (1999), através da equação:

$$
5 \mathrm{Fe}+{ }^{\mathrm{IV}} \mathrm{Al} \rightarrow \mathrm{Si}+2{ }^{\mathrm{VI}} \mathrm{Al}+3 \mathrm{Li}
$$

As equações (3) e (4) são muito similares e, portanto, representativas das variações composicionais da 
(a)
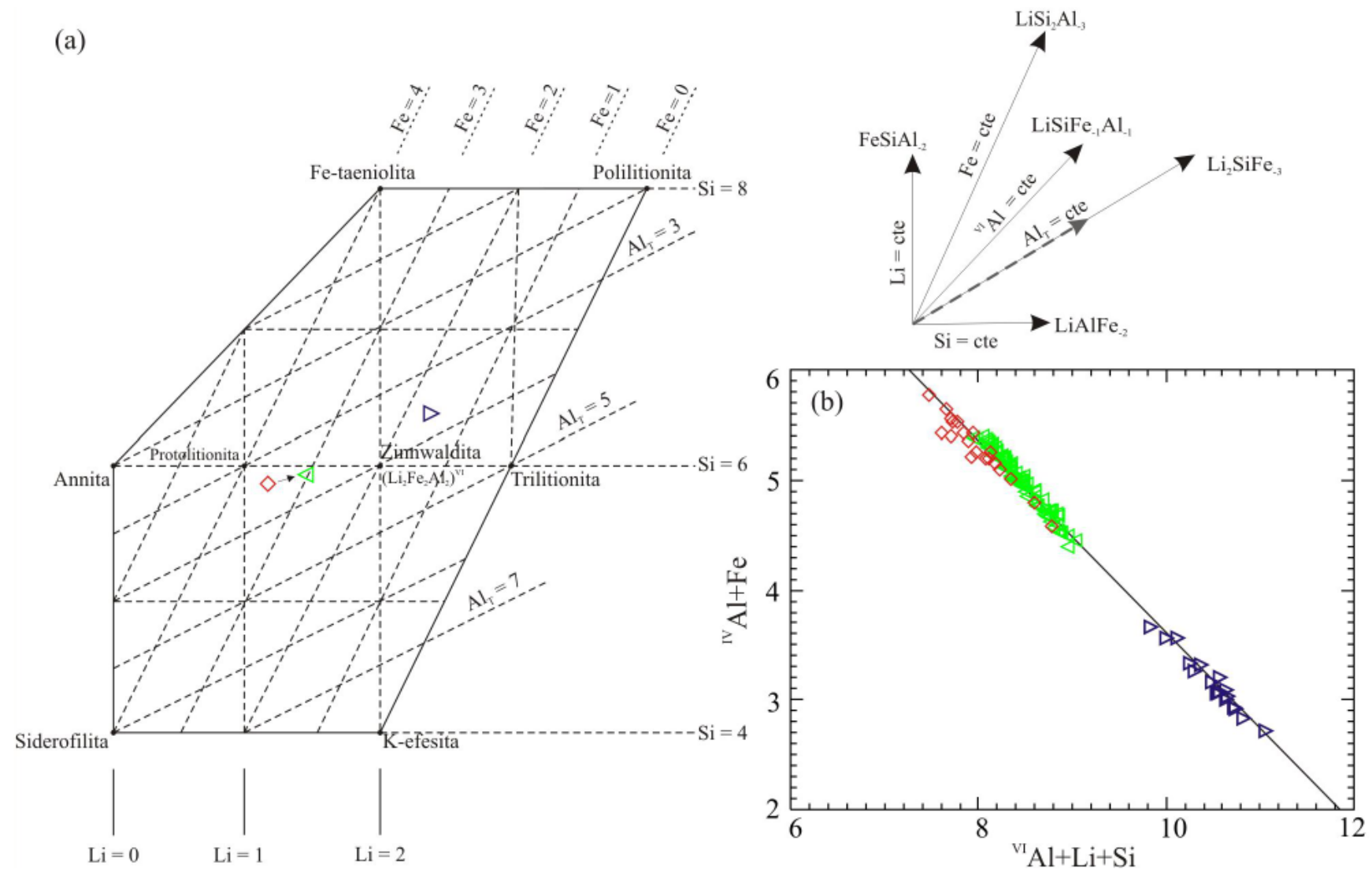

Figura 3 - (a) Diagrama de Cerný \& Burt (1984) para micas trioctaédricas com ${ }^{V I}=0$ e Li, Si, $A l_{T}\left({ }^{V I} \mathrm{Al}+{ }^{I V} \mathrm{Al}\right)$, $\mathrm{Fe}\left(\mathrm{Fe}^{+2}+\mathrm{Zn}+\mathrm{Mn}+\mathrm{Mg}\right) ; \mathrm{O}$ vetor espessado $\left(\mathrm{Li}_{2} \mathrm{SFe}_{-3}\right)$ representa o mecanismo de substituição assumido para as micas analisadas; (b) Diagrama ${ }^{I V} \mathrm{Al}+\mathrm{Fe}\left(\mathrm{Fe}^{+2}+\mathrm{Zn}+\mathrm{Mn}+\mathrm{Mg}\right) v^{-}{ }^{\mathrm{V}} \mathrm{Al}+\mathrm{Li}+\mathrm{Si}$, mostrando as variações nas siderofilitas litiníferas e zinnwalditas e a existência de descontinuidade composicional entre elas.

siderofilita das rochas hidrotermalizadas do Granito Água Boa como um todo.

Embora se verifique aumento nos teores de $\mathrm{Si}$, ${ }^{\mathrm{VI}} \mathrm{Al}$ e Li e diminuição do Fe para as micas tipo zinnwaldita em relação à siderofilita (Fig. 3b), não podemos considerar as duas variedades como fazendo parte de uma série contínua de substituição. Ao que tudo indica, a zinnwaldita, que substitui a siderofilita, formou-se nas mesmas condições e contemporaneamente à mica presente nos veios de quartzo e, portanto, é posterior à greisenização.

Cassiterita Nos greisens de Grota Rica, a cassiterita forma de cristais subédricos a euédricos com granulação média em contato reto com a siderofilita verde; ou ocorre com agregados de granulação variável junto ao topázio, quartzo e fluorita. Mostra intenso zoneamento oscilatório, definidos pela alternância de faixas de coloração vermelho-claro e vermelho-escuro, tanto com zonas de contorno automórfico (Fig. 4a), quanto irregulares (Fig. 4b). No granito ela é bem mais rara e ocorre como finos cristais euédricos em cavidades de dissolução. A cassiterita do greisen da área de Grota Rica é praticamente pura, com $99 \%$ ou mais de Sn. Isto, semelhante ao que foi observado em relação à cassiterita do siderofilita-topázio-greisen da área Guinho-Baixão do plúton Água Boa (Costi et al. 2000, Borges 2002), que também é quase pura, sendo muito pobre em $\mathrm{Nb}+\mathrm{Ta}+$ $\mathrm{Fe}$, porém, com teores relativamente mais altos $\mathrm{em} \mathrm{TiO}_{2}$ do que as cassiteritas magmáticas do albita-granito do Plúton Madeira (Costi et al. 2000) e do topázio-granito associados aos granitos rapakivi da Finlândia (Haapala 1997), interpretadas como sendo de origem magmática. A substituição de $\mathrm{Sn}$ por $\mathrm{Nb}$, Ta e Fe é favorecido por temperaturas altas durante a cristalização da cassiterita (Möller et al. 1988). Portanto, a composição química da cassiterita dos greisens da área Grota Rica reforça as evidências texturais de sua formação em condições subsolidus e de uma origem hidrotermal (cf. Costi et al. 2000).

Esfalerita A esfalerita é a fase mineral mais comum da paragênese sulfetada dos greisens de Pitinga. Apresenta-se de três modos distintos: (1) em cristais anédricos de granulação média a fina, com coloração cinza amarelado, preenchendo cavidades de dissolução no granito; (2) em cristais anédricos de granulação média a fina e cor amarela, preenchendo cavidades no greisen (Fig. 5a); (3) forma cristais anédricos de granulação grossa e coloração alaranjada, geralmente associados à 

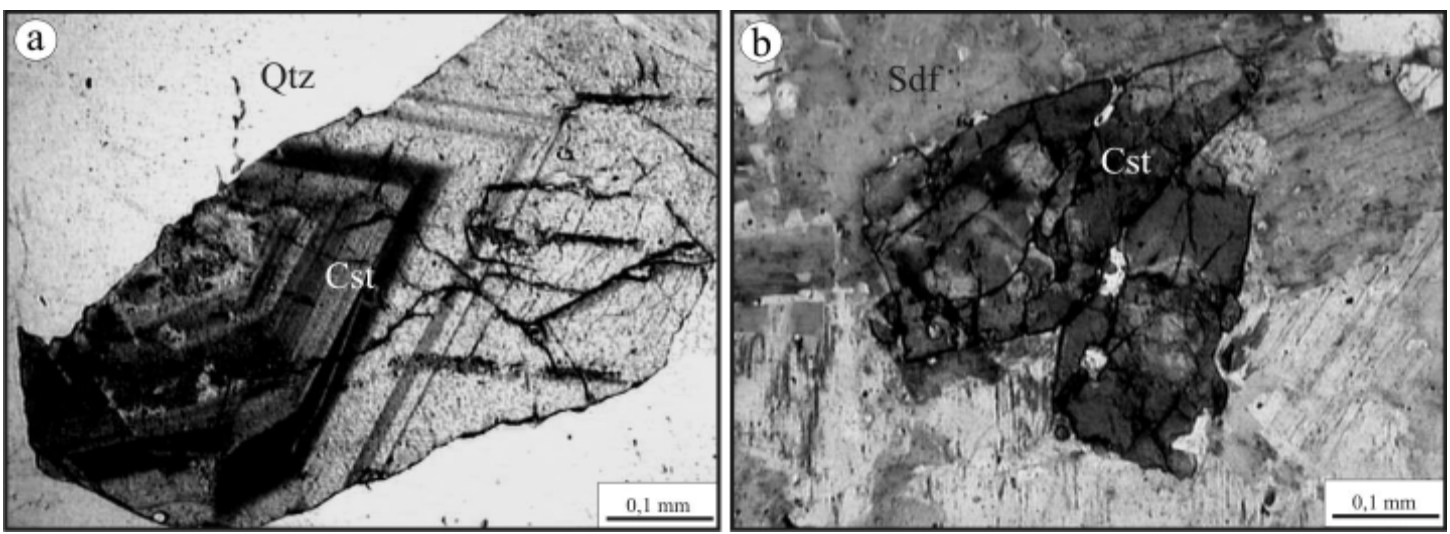

Figura 4 - Aspectos microscópicos de cristais de cassiterita nos greisens. Notar o intenso zoneamento oscilatório com zonas de contorno automófico (a) ou irregular (b). Qtz: quartzo, Cst: cassiterita, Sdf: siderofilita.

zinnwaldita em veios de quartzo (Fig. 5b), os quais possuem conteúdos mais elevados de Fe do que os outros tipos de esfalerita.

Anatásio O anatásio ocorre de dois modos distintos no granito hidrotermalizado: (1) como grãos anédricos, associados à ilmenita e dispostos ao longo das clivagens da annita-siderofilita e possui conteúdos moderados de Ti, Sn e Al; (2) cristais euédricos a subédricos, aparentemente preenchendo cavidades em pseudomorfos (Fig. 6a) e apresenta teores mais elevados de $\mathrm{Ti}$ e Al e mais baixos de $\mathrm{Sn}$ e $\mathrm{Nb}$.

Fluorita A fluorita, presente tanto no topázio-granito quanto no greisen, é comumente anédrica, incolor a levemente lilás e ocorre associada à siderofilita ou preenchendo cavidades. As análises por EDS revelaram que a fluorita apresenta quantidades expressivas de $\mathrm{Y}(\sim 0,8 \%)$ na sua estrutura. A presença de $Y$ pode estar relacionada à substituição de $\mathrm{Ca}$ na estrutura da fluorita. Cesbron (1989) sugere que variações nos conteúdos de ETR e Y podem provocar as diferenças de cor na fluorita.

Monazita A monazita é o principal mineral acessório portador de ETR leves nos greisens estudados. Ocorre como cristais subédricos a anédricos, por vezes arredondados, de tamanho entre 20 e $100 \mu \mathrm{m}$ (Fig. 6b). Dados químicos semiquantitativos permitiram identificar que se trata de Ce-Monazita, com traços de La, Th e Y.

Bismuto nativo Esta fase mineral foi identificada somente no greisen. Forma cristais subédricos a anédricos, inclusos em fluorita, de dimensões menores que $20 \mu \mathrm{m}$.

Pirita A pirita ocorre nos greisens sob a forma de cristais euédricos a subédricos, com bordas localmente corroídas, associada à clorita e esfalerita ou inclusa em quartzo. Encontra-se, aparentemente, em equilíbrio com fases secundárias representativas do estágio de alteração pós-magmática de mais baixa temperatura em relação ao greisen (Fig. 6c).

Galena A galena ocorre em íntima associação com os cristais de pirita, esfalerita, fluorita e clorita nos greisens (Fig. 6c). De modo geral, forma cristais anédricos a subédricos de granulação fina e apresenta conteúdos expressivos de $\mathrm{Fe}, \mathrm{Cu}$ e $\mathrm{Zn}$ em sua estrutura.

CONCLUSÕES O estudo do topázio-granito, greisens e veios de quartzo da área Grota Rica permitiu
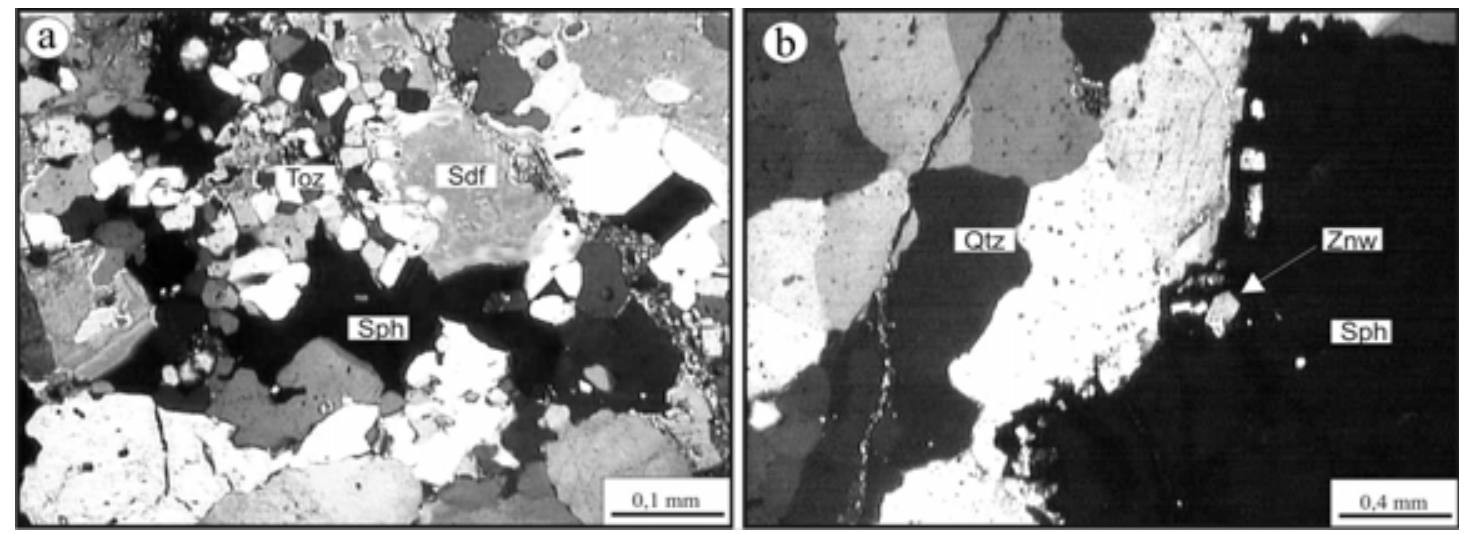

Figura 5 - Feições texturais das variedades de esfalerita. a) em cavidades nos greisens; b) em veios de quartzo. Toz: topázio, Qtz: quartzo, Sph: esfalerita e Znw: zinnwaldita. 

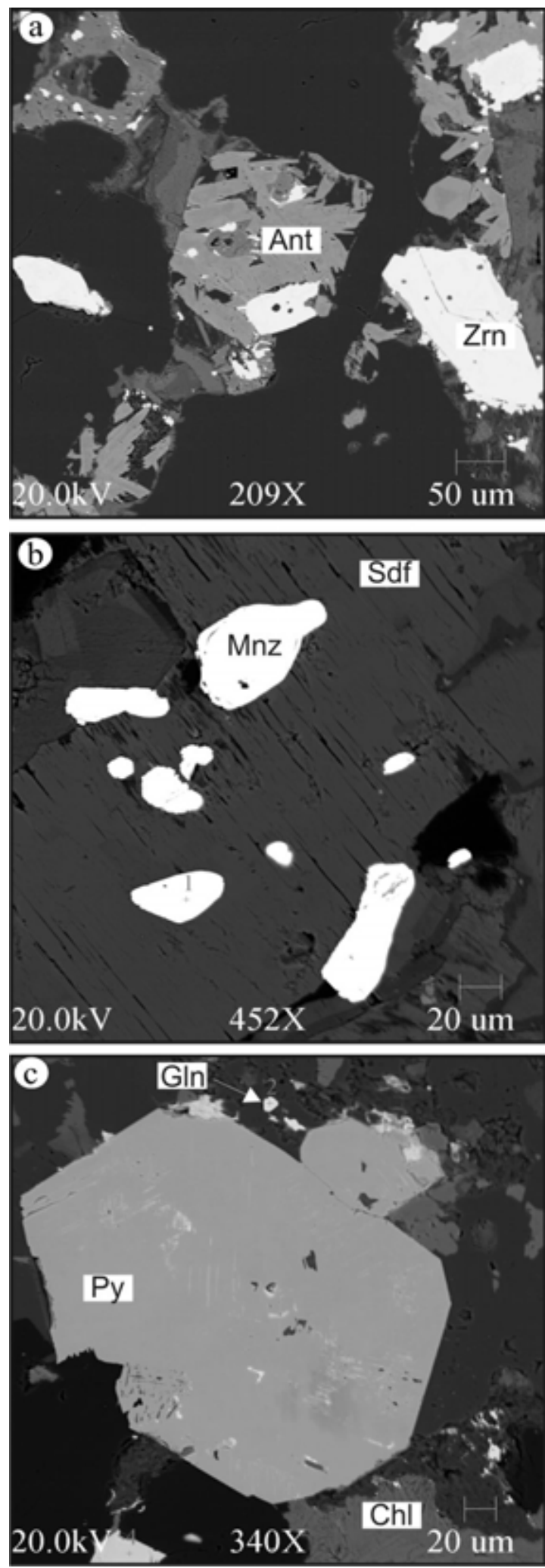

Figura 6 - Imagens obtidas por elétrons retroespalhados e espectros EDS, apresentando feições texturais dos minerais acessórios contidos em cavidades no granito e nos greisens. a) Cristais de anatásio e zircão hidrotermais preenchendo cavidades no granito; b) Cristais de Ce-monazita inclusos em siderofilita; c) Pirita e galena euédricas em contato com quartzo e clorita; Sdf: siderofilita, Ant: anatásio, Zrn: zircão, Mnz: monazita, Py: pirita. a caracterização mineralógica e química das micas e cassiterita presentes nessas rochas, além da identificação de uma grande variedade de minerais de interesse metalogenético potencial, como monazita, anatásio, bismuto nativo, zircão e sulfetos, incluindo esfalerita (mais abundante), pirita e galena. Com exceção da esfalerita, que parece ter se formado durante os diferentes estágios de formação dos greisens, os demais sulfetos (pirita e galena) ocorrem, normalmente, em equilíbrio com fases minerais do estágio de greisenização de mais baixa temperatura (cerca de $270^{\circ} \mathrm{C}$ ) e, provavelmente, devem estar associados à paragênese dos clorita-fengita-greisens (Gs2) (Borges et al. 2003).

As evidências texturais indicam que a mica marrom do topázio-granito formou-se no estágio magmático e foi, posteriormente, afetada por fluidos residuais ricos em flúor e lítio, sendo transformada em uma siderofilita litinífera. A mica verde presente nos greisens também tem composição de siderofilita litinífera, porém é mais rica em Li do que a do granito. Finalmente, as micas pálidas tardias dos greisens e dos veios de quartzo apresentam composição de zinnwaldita. Deduz-se que, no sentido granito $\rightarrow$ greisen, o mecanismo de substituição catiônica implicou trocas entre Fe e ${ }^{\mathrm{IV}} \mathrm{Al}$ por ${ }^{\mathrm{VI}} \mathrm{Al}, \mathrm{Si}$ e Li, partindo da composição da annita em direção à siderofilita litinífera. A zinnwaldita não parece formar uma série contínua com a siderofilita litinífera, embora seja mais enriquecida em ${ }^{\mathrm{VI}} \mathrm{Al}, \mathrm{Si}$ e Li, tendendo para a composição da trilitionita.

O modo de ocorrência e composição muito pura da cassiterita, com baixos conteúdos de $\mathrm{Nb}$ e Ta, fortalecem a hipótese de sua formação em condições hidrotermais, uma vez que as cassiteritas magmáticas do albita-granito do Plúton Madeira (Costi et al. 2000) e do topázio-granito associados aos granitos rapakivi da Finlândia (Haapala 1997), apresentam quantidades significativas de Nb, Ta e Fe (Costi et al. 2000).

Agradecimentos Agradecemos aos pesquisadores do Grupo de Pesquisa Petrologia de Granitoides (GPPG), pelo apoio nas diversas etapas deste trabalho; ao Grupo Paranapanema S/A, pela liberação dos testemunhos de sondagem e aos geólogos da empresa pelo apoio logístico nas etapas de campo; ao químico Marcos Mansueto e ao Prof. Silvio Vlach do IGc/USP, pelo apoio nas análises de microssonda eletrônica; ao $\mathrm{CNPq}$, pela concessão da bolsa de mestrado à primeira autora; ao Programa de Pós-graduação em Geoquímica e Petrologia e ao Instituto de Geociências (IG/UFPA) pelo suporte técnico. Este trabalho foi desenvolvido no quadro do subprojeto "Depósitos de Estanho da mina Pitinga, Estado do Amazonas", que faz parte do projeto "Caracterização de Depósitos Minerais em Distritos Mineiros da Amazônia", cuja execução foi apoiada pelo convênio FINEP/DNPM/ADIMB. Este artigo é uma contribuição ao projeto IGCP-510 e ao INCT Geociam (Programa INCT - CNPq/MCT/FAPESPA - Proc. $573733 / 2008-2)$. Os agradecimentos são extensivos a Lena V. Monteiro pela revisão do artigo. 


\section{Referências}

Almeida F.F.M., Hasui Y., Brito Neves B.B., Fuck R.A. 1981. Brazilian structural Provinces: An introduction. Earth Sciences Reviews, 17:1-29.

Almeida M.E. 2006. Evolução Geológica da porção centro-sul do escudo das Guianas com base no estudo Geoquímico, Geocronológico (Evaporação de Pb e U-Pb ID-TIMS em zircão) e isotópico ( $\mathrm{Nd}-\mathrm{Pb}$ ) dos granitoides Paleoproterozoicos do sudeste de Roraima. Tese de Doutorado, Instituto de Geociências, Universidade Federal do Pará, Belém, 227 p.

Araújo Neto H. \& Moreira H.L. 1976. Projeto Estanho Abonari. Manaus, ME/DNPM/CPRM, Relatório final, $232 \mathrm{p}$.

Borges R.M.K. 1997. Petrografia e química mineral dos greisens associados ao Granito Água Boa - Mina Pitinga (AM): Um estudo dos processos de formação de greisens. Dissertação de Mestrado, Instituto de Geociências, Universidade Federal do Pará, Belém, $190 \mathrm{p}$.

Borges R.M.K. 2002. Greisens e epissienitos potássicos associados ao Granito Água Boa, Pitinga (AM): Um estudo dos processos hidrotermais geradores de mineralizações estaníferas. Tese de Doutorado, Instituto de Geociências, Universidade Federal do Pará, Belém, $383 \mathrm{p}$.

Borges R.M.K., Dall'Agnol R., Costi H.T. 2003. Geologia, petrografia e química mineral das micas dos greisens estaníferos associados ao plúton Água Boa, Pitinga (AM). Revista Brasileira de Geociências, 33(1):51-62.

Borges R.M.K., Villas R.N.N., Fuzikawa K., Dall'Agnol R., Pimenta M.A. 2009. Phase separation, fluid mixing, and origin of the greisens and potassic episyenite associated with the Água Boa plúton, Pitinga tin province, Amazonian Craton, Brazil. J. S. Am. Earth. Sci., 27:161-183.

Cerný P. \& Burt D.M. 1984. Paragenesis, crystalochemical characteristics, and geochemical evolution of micas in granite pegmatites. In: Bailey S.W. (ed.) Micas - Reviews in Mineralogy. New York, Mineralogical Society of American, p. 257-298.

Cesbron F.P. Lanthanides, Tantalum and Niobium. 1989. In: Möller R., Cerný P., Saupé F. (eds.) Mineralogy of the Rare Earth Elements. Brelin, Springer-Verlag, p. 3-26.

Costi H.T., Borges R.M.K., Dall'Agnol R. 2005. Depósitos de estanho da Mina Pitinga, Estado do Amazonas. In: Marini O.J., Queiroz E.T., Ramos B.W. (eds.) Caracterização de depósitos minerais em distritos mineiros da Amazônia. Brasília, DNPM/CT-Mineral FINEP/ADIMB, p. 391-475.

Costi H.T., Dall'Agnol R., Moura C.A.V. 2000. Geology and $\mathrm{Pb}-\mathrm{Pb}$ Geochronology of Paleoproterozoic Volcanic and Granitic rocks of Pitinga Province, Amazonian Craton, Northern Brazil. International Geology Reviews, 42:832-849.

Costi H.T., Dall'Agnol R., Borges R.M.K., Minuzzi O.R.R., Teixeira J.T. 2002. Tin-Bearing Sodic Episyenites Associated with the Proterozoic, A-Type Água Boa Granite, Pitinga Mine, Amazonian Craton, Brazil. Gondwana Research., 5:435-451.
Costi H.T., Dall'Agnol R., Pichavant, M, Ramo, O.T. 2009. The peralkaline tin-mineralized madeira cryolite albite-rich granite of Pitinga, Amazonian craton, brazil: petrography, mineralogy and crystallization processes. The Canadian Mineralogist, 47:1301-1327.

Daoud W.K. 1988. Granitos Estaniferos de Pitinga, Amazonas: Contexto Geológico e Depósitos Minerais Associados. Dissertação de Mestrado, Instituto de Geociências, Universidade de Brasília, Brasília, 194 p.

Daoud W.K. \& Antonietto Jr. A. 1985. Geologia do Granito Água Boa, Pitinga, AM. In: SBG, Simpósio de Geologia da Amazônia, 2, Anais, p. 17-33.

Feio G.R.L., Dall'Agnol R., Borges R.M.K. 2007. Greisens associados ao topázio-granito do plúton Água Boa, Província Estanífera de Pitinga: Petrografia e Balanço de massa. Revista Brasileira de Geociências, 37(3):2-17.

Feio G.R.L. 2007. Petrografia e Geoquímica dos greisens associados ao topázio-granito do plúton Água Boa, Província Estanífera de Pitinga (AM). Dissertação de Mestrado, Instituto de Geociências, Universidade Federal do Pará, Belém, 132 p.

Feio G.R.L., Dall'Agnol R., Borges R.M.K. 2006. Estudos dos minerais acessórios de epissienitos e greisens da Província estanífera de Pitinga. In: SBG, Simpósio de Geologia da Amazônia, 9, Belém, Resumos Expandidos, 1 CD-Rom.

Ferron J.M.T.M. 2006. Geologia regional, Geoquímica e Geocronologia $\mathrm{Pb}-\mathrm{Pb}$ de rochas graniticas $e$ vulcânicas paleoproterozóicas da Província Pitiga, Cráton Amazônico. Tese de Doutorado, Instituto de Geociências, Universidade Federal do Rio Grande do Sul, Porto Alegre, $331 \mathrm{p}$.

Ferron J.M.T.M., Neto, A.C.B., Lima E.F.de., Costi H.T., Moura C.A.V., Prado M., Pierosan R., Galarza M.A. 2006. Geologia e Geocronologia $\mathrm{Pb}-\mathrm{Pb}$ de rochas graníticas e vulcânicas ácidas a intermediárias Paleoproterozóicas da Província Pitinga, Cráton Amazônico. Revista Brasileira de Geociências, 36(3):499-512.

Foster M.D. 1960. Layer charge relations in the dioctahedral and trioctahedral micas. American Mineralogist, 45:383398.

Gibbs A.K. \& Barron C. 1983. The Guiana shield reviewed. Episodes, 6:7-14.

Haapala I. 1997. Magmatic and postmagmatic processes in tin-mineralized granites: topaz bearing leucogranite in the Eurajoki Rapakivi Granite stock, Finland. Journal of Petrology, 12:1645-1649.

Horbe M.A., Horbe A.C., Teixeira J.T., Costi H.T. 1985. Granito Madeira: Petrologia, Petroquímica e Mineralizações. In: SBG, Simp. Geol. Amazônia, 3, Anais, p. 284-320.

Horbe M.A., Horbe A.C., Costi H.T., Teixeira J.T. 1991. Geochemical characteristics of cryolite-tin-bearing granites from Pitinga Mine, northwestern Brazil - A review. Journal of Geochemical Exploration, 40:227249.

Lenharo S.L.R. 1998. Evolução magmática e modelo metalogenético dos granitos mineralizados da região de 
Pitinga, Amazonas, Brasil. Tese de Doutorado, Escola Técnica da Universidade de São Paulo, Universidade de São Paulo, São Paulo, 290 p.

Lenharo S.L.R., Moura M.A., Botelho N.F. 2002. Petrogenetic and mineralization processes in Paleo to Mesoproterozoic rapakivi granites: examples from Pitinga and Goiás, Brazil. Precambrian Research, 119:277-299.

Lenharo S.L.R., Pollard P.J., Born H. 2003. Petrology and textural evolution of granites associated with tin and raremetals mineralization at the Pitinga mine, Amazonas, Brazil. Lithos, 66:37-61.

Minuzzi O.R.R. 2005. Gênese e evolução da mineralização de criolita, pirocloro e columbita da subfácies albita granito de núcleo, mina Pitinga, Amazonas, Brasil. Tese de Doutorado, Universidade Federal do Rio Grande do Sul, Porto Alegre, $182 \mathrm{p}$.

Minuzzi O.R.R., Bastos Neto A.C., Formoso M.L.L., Andrad, S., Janasi V.A., Flores J.A.A. 2008. Rare earth element and yttrium geochemistry applied to the genetic study of cryolite ore at the Pitinga mine (Amazon, Brazil). An. Acad. Bras. Ciênc. 80:719-733.

Möller P., Dulski P., Skacki W., Malow G., Riedel E. 1988. Substitution of tin in cassiterite by tantalum, niobium, tugsten, iron and manganese. Geochemical et Cosmochimica Acta, 52:1497-1503.

Moura M.A. \& Botelho N.F. 1994. Estudo de micas litiníferas e sua importância para a caracterização das rochas da zona greisenizada principal do Maciço Estanífero de Mangabeira, GO. Boletim de Geociências do CentroOeste, 17:39-48.

Rieder M., Cavazzini G., D’Yakonov Y.S., FrankKamenetskii V.A., Gottardi G., Guggenheim S., Koval P., Müller G., Neiva A.M.R., Radoslovich E.W., Robert J.L., Sassi F.P., Takeda H., Weiss Z., Wones D.R. 1998. Nomenclature of the micas. The Canadian Mineralogist, 36:905-912.

Santos J.O.S., Hartmann L.A., Gaudette H.E., Groves D.I., McNaugthon N.J., Fletcher L.R.A. 2000. New understanting of the Provinces of Amazon Craton based on Integration of Field Mapping and U-Pb and $\mathrm{Sm}-\mathrm{Nd}$ geochronology. Gondwana Research 3(4):453-488.

Santos J.O.S., Hartmann L.A., MCnaughton N.J., Fletchu I.R. 2002. Timing of mafic magmatism in the Tapajós Province (Brazil) and implications for the evolution $\mathrm{f}$ the Amazon Craton: evidence from baddeleyite and zircon U-Pb SHRIMP geochronology. Journal of South American Earth Sciences, 15:409-429.

Souza V.S. \& Botelho N.F. 2002. Geologia do depósito de estanho do Bom Futuro (Rondônia) e composição dos fluidos nos sistemas de veios e greisens. In: Klein E.L., Vasquez M.L., Rosa-Costa L.T. (eds.) Contribuições à Geologia da Amazônia. Belém, SBG-NO, p. 199-214.

Sparrenberger I. 2003. Evolução da mineralização primária estanífera associada ao Maciço Granítico Santa Bárbara, Rondônia. Tese de Doutorado, Instituto de Geociências, Universidade de São Paulo, São Paulo, 252 p.

Stone M., Exley C.S., George M.C. 1988. Compositions of trioctahedral micas in the Cornubian batholith. Mineralogical Magazine, 52:175-182.

Sun S., Yu J. 1999. Fe-Li micas: a new approach to the substitution series. Mineralogical Magazine, 63(6):933945.

Tassinari C.C.G. \& Macambira M.A. 2004. Evolução Tectônica do Craton Amazônico. In: Mantesso-neto V., Bartorelli A., Carneiro C.D.R., Brito Neves B.B. de (eds.) Geologia do Continente Sul Americano: Evolução da obra de F.F.M. de Ameida. São Paulo, BECA, p. 471486.

Tindle A.G. \& Webb P.C. 1990. Estimation of lithium contents in trioctahedral micas using microprobe data: application to micas from granitic rocks. European Journal of Mineralogy, 2:595-610.

Tischendorf G., Gottesmann B., Forster H.J., Trumbull R.B. 1997. On Li-bearing micas: Estimating Li from electron microprobe analysis and an improved diagram for graphical representation. Mineralogical Magazine, 61:809-834.

Tischendorf G., Rieder M., Forster H.J., Gottesmann B., Guidotti C.V. 2004. A new graphical presentation and subdivision of potassic micas. Mineralogical Magazine, 68(4):649-667.

Tuttle O.F. \& Bowen N.L. 1958. Origin of granite in the light of experimental studies in the system $\mathrm{NaAl} \mathrm{Si}_{3} \mathrm{O}_{8}$ - $\mathrm{KAlSi}_{3} \mathrm{O}_{8}-\mathrm{SiO}_{2}-\mathrm{H}_{2}$ O. Geol. Soc. Amer. Mem., 74:1153.

Valério C.S., Souza V.S., Macambira M.J.B. 2009. The 1.901.88 Ga magmatism in the southernmost Guyana Shield, Amazonas, Brazil: Geology, geochemistry, zircon geochronology, and tectonic implications. Journal of South American, 28(3):304-320.

Veiga Jr. J.P., Nunes A.C.B., Souza E.C.D., Santos J.O.S., Amaral J.E. de, Pessoa M.R., Souza S.A.S. 1979. Projeto sulfetos de Uatumã. Manaus, DNPM/CPRM, Relatório técnico final 6, $1.635 \mathrm{p}$.

Manuscrito ID 17958

Submetido em 01 de março de 2011 Aceito em 13 de outubro de 2011 